\title{
Estabelecimento in vitro de aroeira da praia (Schinus terebinthifolius Raddi) em diferentes concentrações de 6-benzilaminopurina (BAP)
}

\section{PAIVA, A.M.S.; ; ALOUFA, M.A.I.}

Universidade Federal do Rio Grande do Norte (UFRN). Av. Senador Salgado Filho, Centro de Biociências, Departamento de Botânica, Ecologia e Zoologia. Campus Universitário, Lagoa Nova. CEP 59072-970. Natal/RN. *alessandralivia@yahoo.com.br; magdi-aloufa@bol.com.br

\begin{abstract}
RESUMO: A aroeira da praia (Schinus terebinthifolius Raddi) é Anacardiaceae com propriedades medicinais extensamente exploradas por populares, no tratamento de inflamações uterinas, principalmente na região Nordeste do Brasil. O objetivo desse estudo foi estabelecer concentrações ideais de 6-Benzilaminopurina (BAP) para o estabelecimento in vitro de Schinus terebinthifolius através de segmentos nodais, internodais, cotiledonares e ápices caulinares. Os explantes foram cultivados em meio MS, suplementado com $3 \%$ de sacarose, $0,1 \mathrm{~g} \mathrm{~L}^{-1}$ de mio-inositol e concentrações distintas de BAP: $0 ; 2,25 ; 4,5 ; 9,0 ; 18,0 \mu \mathrm{M}$. As características avaliadas foram a indução de brotos, número e comprimento dos brotos. Foi observado que, para o estabelecimento in vitro da aroeira da praia, o explante mais indicado é o segmento nodal. Os segmentos internodais desenvolvem apenas calos, não havendo indução de brotos adventícios. O tratamento com 4,5 $\mu \mathrm{M}$ de BAP é o mais responsivo para a regeneração de Schinus terebinthifolius.
\end{abstract}

Palavras-chave: Schinus terebinthifolius, plantas medicinais, micropropagação

\begin{abstract}
In vitro establishment of Brazilian pepper (Schinus terebinthifolius Raddi) at different concentrations of 6-benzylaminopurine. Brazilian pepper (Schinus terebinthifolius Raddi) is Anacardiaceae presenting medicinal proprieties which are extensively exploited by common citizens to treat uterine inflammation, especially in the northeast region of Brazil. The aim of this study was to establish ideal concentrations of 6-benzilaminopurine (BAP) for the in vitro establishment of Schinus terebinthifolius using nodal, internodal, cotyledonary and apical stem segments. Explants were cultured on MS medium supplemented with $3 \%$ sucrose, $0.1 \mathrm{~g} \mathrm{~L}^{-1}$ myoinositol and distinct concentrations of BAP: $0,2.25,4.5,9.0$ and $18.0 \mu \mathrm{M}$. The evaluated parameters were sprout induction, and sprout number and length. Nodal segment is the most suitable explant for the in vitro establishment of Brazilian pepper. Internodal segments only develop callus, not inducing adventitious sprouts. The treatment with $4.5 \mu \mathrm{MBAP}$ was the most responsive to Schinus terebinthifolius regeneration.
\end{abstract}

Key words: Schinus terebinthifolius, medicinal plants, micropropagation

\section{INTRODUÇÃO}

A exploração extrativista de diversas espécies de plantas com propriedades medicinais vem provocando erosão genética e colocando-as em risco de extinção. A propagação in vitro de plantas medicinais tem sido realizada por vários pesquisadores e incrementada nos últimos anos devido a vários fatores, entre eles, dificuldades na reprodução, baixa taxa de germinação ou exploração irracional, resultando na quase extinção de algumas espécies e modificação do meio ambiente, dificultando a coleta de plantas saudáveis (Sabá et al., 2002).
Schinus terebinthifolius Raddi, conhecida popularmente como aroeira da praia, aroeira vermelha, aroeira pimenteira e aroeira mansa, é Anacardiaceae encontrada em terrenos arenosos da Mata Atlântica do Nordeste do Brasil, estendendo-se pelo cerrado até o Rio Grande do Sul, Argentina e Paraguai (Amorim, 2003). Esta espécie possui crescente uso farmacológico; é considerada pela medicina popular como adstringente, antidiarréica, antiinflamatória, depurativa, diurética e febrífuga. A casca e as folhas são as partes que apresentam utilização fitoterápica,

Recebido para publicação em 04/08/2008

Aceito para publicação em 21/12/2008 
sendo suas propriedades atribuídas à diversidade de constituintes químicos deste vegetal, tais como os taninos e os polifenóis (Matos, 2002).

Considerando a utilização medicinal, sendo o extrato da casca amplamente utilizado pela indústria farmacêutica, ainda são poucos os estudos sobre a propagação desta espécie. As técnicas de micropropagação seriam alternativa viável, pois, a clonagem de mudas individuais promove plantas com material genético uniforme, o que seria uma fonte satisfatória para procedimentos industriais de extração de combinações de interesse. Segundo Oliveira (2003), a utilização de material geneticamente uniforme, seria viável para se obter protocolos para extração de princípios ativos podendo esses ser unificados.

O tipo de citocinina e a concentração são os fatores que mais influenciam o sucesso da multiplicação in vitro. A 6-benzilaminopurina (BAP) tem sido muito eficaz para promover a multiplicação de diversas espécies e parece ser a citocinina por excelência para multiplicação de partes aéreas e indução de gemas adventícias. Isso parece ocorrer por razão dos tecidos vegetais responderem aos hormônios naturais mais rapidamente do que aos reguladores de crescimento sintéticos (Grattapaglia \& Machado, 1998).

$\mathrm{Na}$ literatura, existe uma série de trabalhos sobre a propagação in vitro de diversas espécies da família Anacardiaceae, porém algumas são negligenciadas, a exemplo de aroeira da praia. Sendo assim, este trabalho objetivou desenvolver um protocolo para regeneração direta de brotos em Schinus terebinthifolius Raddi. O estudo é parte do processo de micropropagação, que possibilitará homogeneidade na produção de mudas com características genéticas de interesse e qualidade fitossanitária, mudas essas, que poderão ser utilizadas pela indústria farmacêutica para extração do princípio ativo, evitando a exploração extrativista.

\section{MATERIAL E MÉTODO}

O trabalho foi realizado no Laboratório de Cultura de Tecidos Vegetais do Departamento de Botânica, Ecologia e Zoologia do Centro de Biociências da Universidade Federal do Rio Grande do Norte. Os frutos foram coletados de espécimes de Schinus terebinthifolius Raddi encontrados no rio Ceará-Mirim, município de Extremoz/RN As sementes foram germinadas em condições de casa de vegetação, onde foi mantido banco de germoplasma.

Ramos jovens de aroeira com $15 \mathrm{~cm}$ de comprimento, aproximadamente, foram coletados de plantas com 4 a 8 meses de idade, cultivadas em casa de vegetação. Após remoção das folhas, os ramos foram desinfestados em câmara de fluxo laminar, através da imersão em etanol a $70 \%$, por 3 minutos, e em solução de hipoclorito PA de sódio com taxa de cloro ativo a 2\%. Após a desinfestação, os mesmos foram lavados 3 vezes com água destilada autoclavada, por 10 minutos cada, para posterior retirada dos explantes.

Os explantes utilizados foram segmentos cotiledonares $(5 \times 5 \mathrm{~mm})$, segmentos nodais com um único nó $(10 \mathrm{~mm})$, segmentos internodais (10 $\mathrm{mm}$ ), e ápices caulinares $(10 \mathrm{~mm})$. Os explantes foram colocados individualmente em frascos de $100 \mathrm{~mL}$ de capacidade contendo $30 \mathrm{~mL}$ de meio MS (Murashige \& Skoog, 1962) suplementado com $3 \%$ de sacarose, $0,1 \mathrm{~g} \mathrm{~L}^{-1}$ de mio-inositol, $6,0 \mathrm{~g} \mathrm{~L}^{-1}$ de ágar e concentrações distintas de 6- Benzilaminopurina (BAP): 0,0 $\mu \mathrm{M}, \mathrm{T} 0 ; 2,25 \mu \mathrm{M}, \mathrm{T} 1 ; 4,5 \mu \mathrm{M}, \mathrm{T} 2 ; 9 \mu \mathrm{M}$, $\mathrm{T} 3$ e $18 \mu \mathrm{M}, \mathrm{T} 4$. O pH foi ajustado para 5,8 antes da autoclavagem, realizada a $121^{\circ} \mathrm{C}$ por 20 minutos. Os explantes foram mantidos no escuro por 7 dias, em sala de crescimento com temperatura de $25 \pm 2^{\circ} \mathrm{Ce}$ depois transferidas para fotoperíodo de 12 horas, com intensidade luminosa de $27 \mu \mathrm{mol} \mathrm{m} \mathrm{m}^{-2} \mathrm{~s}^{-1}$ a mesma temperatura.

O delineamento experimental utilizado foi o inteiramente casualizado (DIC) não balanceado, com 3 repetições de 10 unidades experimentais, totalizando 30 explantes para cada tratamento. Aos 45 dias após o cultivo foram avaliadas as características taxa de indução de brotos, número e altura dos brotos. Os dados foram comparados pelo teste de Tukey a $5 \%$ de significância.

Os brotos obtidos foram colocados em meio para alongamento composto de sais e vitaminas de $\mathrm{MS}$, adicionado de $3 \%$ de sacarose, $0,1 \mathrm{~g} \mathrm{~L}^{-1}$ de mioinositol e 2,88 $\mu \mathrm{M}$ de ácido giberélico $\left(\mathrm{GA}_{3}\right)$. Aos 30 dias após a inoculação, avaliou-se o crescimento médio dos brotos. $O$ delineamento utilizado foi inteiramente casualizado (DIC) balanceado. Os dados foram comparados pela análise de correlação linear simples.

\section{RESULTADO E DISCUSSÃO}

Segmentos cotiledonares e ápices caulinares apresentaram alto nível de oxidação fenólica, impedindo o prosseguimento das culturas, concordando com Das et al. (1996) que observaram o escurecimento e morte dos explantes após 15-20 dias de cultivo provenientes de cajueiros cultivados em casa de vegetação. Aoxidação fenólica é um dos problemas que dificultam o estabelecimento inicial do cultivo in vitro, ocorrendo a liberação de compostos fenólicos devido a injuria causada nos tecidos durante a excisão dos explantes. Segundo Flores et al. (1998), algumas enzimas oxidam os fenóis formando quinonas, que são responsáveis pela coloração 
marrom das culturas, além de causarem a inibição do crescimento e morte dos explantes em grande número de espécies.

Aos 7 dias após a inoculação verificou-se o início de calogênese nos segmentos nodais em regiões próximas ao nó, enquanto o aparecimento de brotos foi observado a partir do décimo quinto dia de cultivo in vitro. Foi verificado por Carvalho et al. (2002) a indução de brotos a partir de segmentos nodais de cajazeira (Spondias mombin L.) após duas semanas de cultivo em meio WPM Lloyd \& Mc Cown (1980) com diferentes concentrações de BAP. Ao contrário do observado para segmentos nodais, os segmentos internodais desenvolveram apenas calos, não havendo indução de brotos adventícios. De acordo com o observado, apenas o segmento nodal mostrouse viável e responsivo para regeneração in vitro de $S$. terebinthifolius.

Os segmentos nodais submetidos ao tratamento T2 $(4,5 \mu \mathrm{M}$ de BAP) apresentaram a maior taxa de indução de brotos (86,6\%) (Figura 1). Resultados similares foram obtidos por Andrade et al. (2000), que ao trabalharem com aroeira do sertão (Myracrodruon urundeuva Fr. All.), alcançaram as maiores taxas de regeneração $(90 \%)$ na concentração de $4,5 \mu \mathrm{M}$ de BAP. Os tratamentos com T0 $(0,0)$ e T1 $(2,25 \mu \mathrm{M})$ apresentaram taxa de indução de brotos significativamente iguais, enquanto que os tratamentos T3 $(9,0 \mu \mathrm{M})$ e T4 $(18 \mu \mathrm{M})$ foram ineficientes para obtenção de brotos, causando apenas o aparecimento de calos. Boggetti et al. (1999), estudando a morfogênese de caju (Anacardium occidentale L.), também verificaram a formação de calos em explantes cultivados em meio nutritivo com $20 \mu \mathrm{M}$ de BAP. Mneney \& Mantell (2002) relatam que concentrações de BAP acima de $20 \mu \mathrm{M}$ suprimiram a formação de brotos a partir de segmentos nodais de caju.

Os tratamentos $\mathrm{T} 1$ (2,25 $\mu \mathrm{M}$ de BAP) e T2 (4,5 $\mu \mathrm{M}$ de BAP) diferenciaram, em média, 2 brotos por segmento nodal, diferindo significativamente do tratamento sem regulador de crescimento (Figura 2). Os resultados observados para a regeneração de $S$. terebinthifolius Raddi são significativos quando comparados à trabalhos anteriores realizados com plantas aparentadas. Andrade et al. (2000) obtiveram a regeneração de apenas um broto de Myracrodruon urundeuva Fr. All. por segmento nodal, utilizando um meio suplementado com 2,3 $\mu \mathrm{M}$ e 4,5 $\mu \mathrm{M}$ de BAP. Sabá et al. (2002), trabalhando com a micropropagação do jaborandi, obtiveram 1,8 brotos por explante na concentração de 6,66 $\mu \mathrm{M}$ de BAP. Entretanto Das et al. (1996) observaram a formação de 10-12 brotos de A. occidentale L. por explante em meio MS com 4,4 $\mu \mathrm{M}$ de BAP, 2,32 $\mu \mathrm{M}$ de CIN e 9,12 $\mu \mathrm{M}$ de ZEA. Esse fato mostra que a proliferação de brotos in vitro

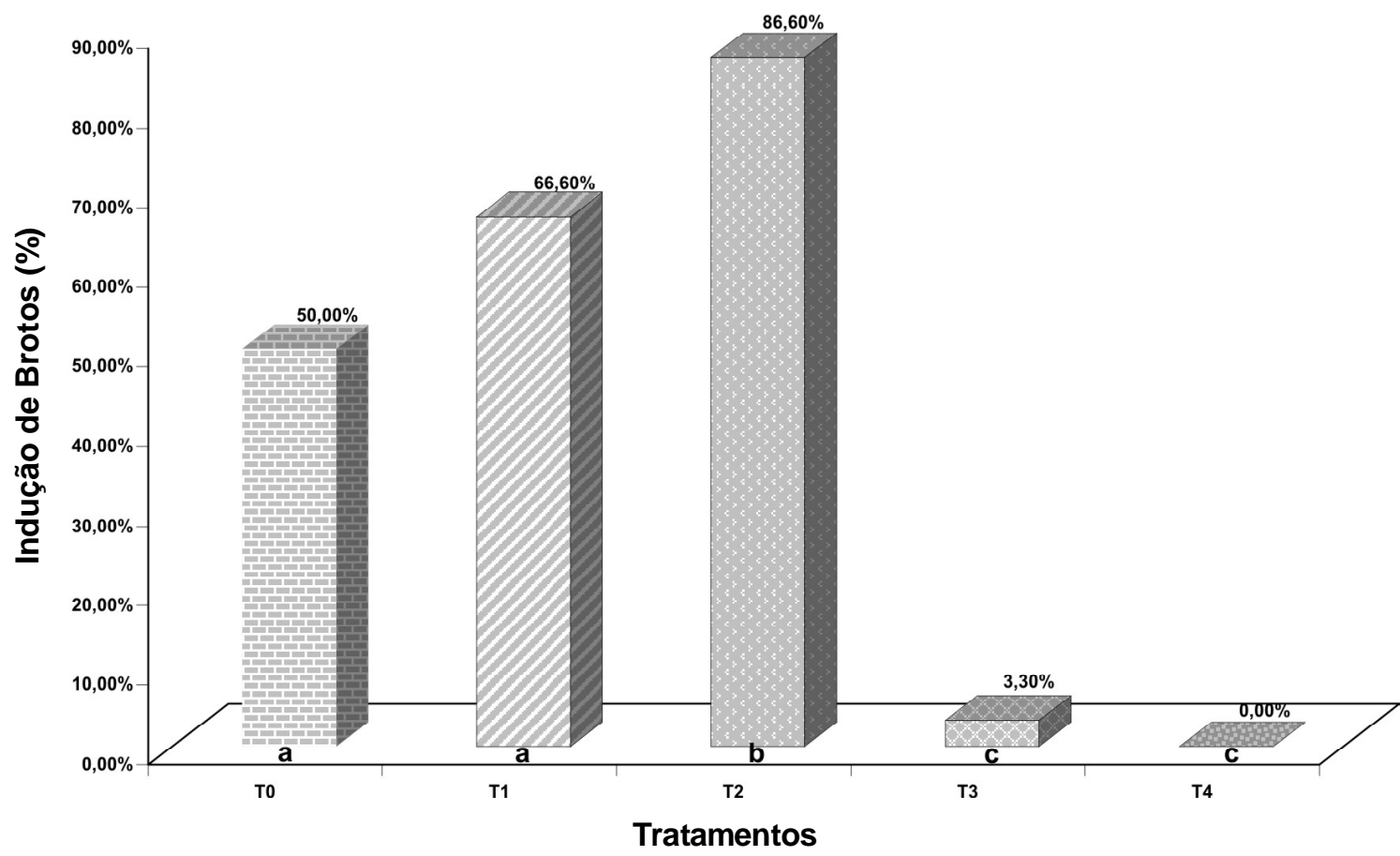

FIGURA 1. Taxa de indução de brotos (TIB\%) de Schinus terebinthifolius a partir de segmentos nodais cultivados em diferentes concentrações de BAP. T0: controle; T1:2,25 $\mu \mathrm{M}$ de BAP; T2: 4,5 $\mu \mathrm{M}$ de BAP; T3: 9,0 $\mu \mathrm{M}$ de BAP; T4: $18 \mu \mathrm{M}$ de BAP. Médias com letras iguais não diferem entre si segundo o teste de Tukey a $5 \%$ de significância. 


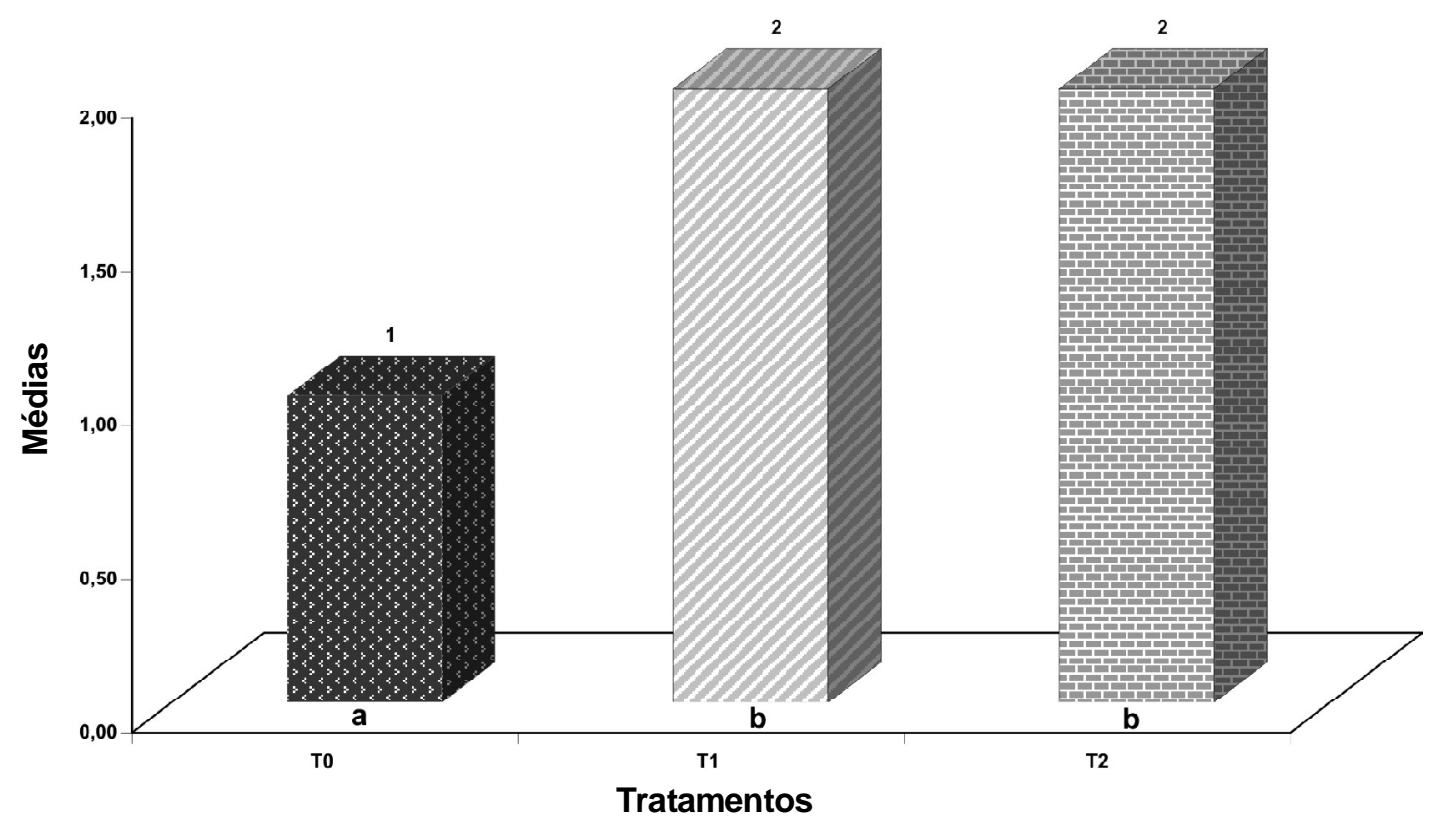

FIGURA 2. Número médio de brotos por explante em função de diferentes tratamentos, no cultivo in vitro de segmentos nodais de aroeira da praia. T0: controle;T1:2,25 $\mu \mathrm{M}$ de BAP; T2: 4,5 $\mu \mathrm{M}$ de BAP. Médias com letras iguais não diferem entre si segundo o teste de Tukey a $5 \%$ de significância.

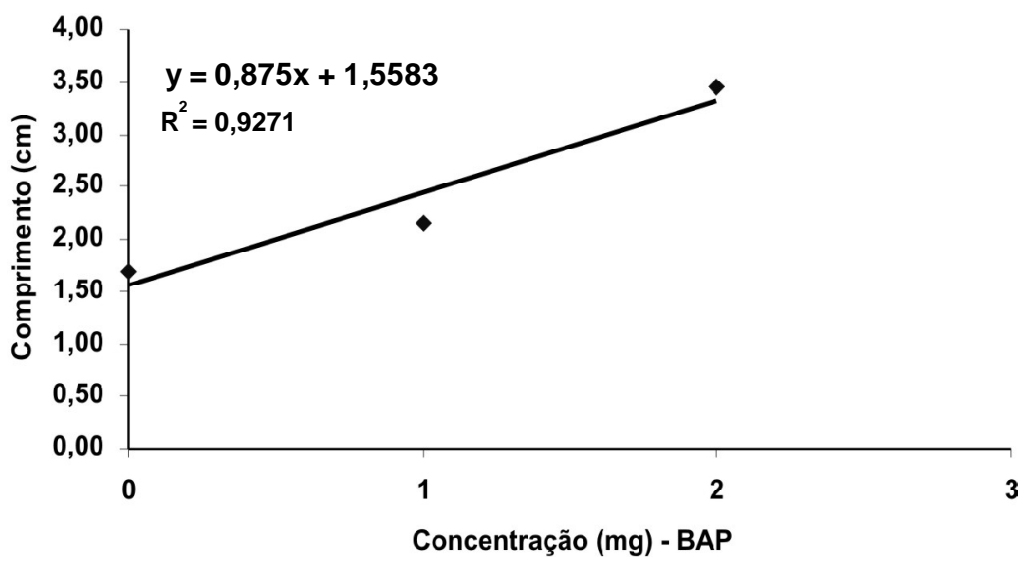

FIGURA 3. Médias do comprimento de Schinus terebinthifolius a partir de segmentos nodais cultivados em diferentes concentrações de BAP. T0: controle; T1:2,25 $\mu \mathrm{M}$ de BAP; T2: 4,5 $\mu \mathrm{M}$ de BAP.

pode ser maximizada com o emprego de dois ou mais reguladores de crescimento. Talvez a proliferação de número maior de brotos de $S$. terebinthifolius Raddi necessite da combinação entre mais de uma citocinina, ou de citocininas com auxinas.

Aos 45 dias de cultivo não foi verificada diferença significativa no comprimento dos brotos entre os tratamentos T1 e T2, com médias de $2,15 \mathrm{~cm}$ e $3,45 \mathrm{~cm}$, respectivamente. No entanto, o tratamento T2 induziu brotos com comprimentos médios significativamente maiores que o T0 (Figura 3). Concordando com esse resultado observado, Andrade et al. (2000) obtiveram os maiores brotos de $M$. urundeuva Fr. All. em tratamento com 4,5 $\mu$ M de BAP.

Os brotos originários da fase de regeneração foram todos tratados com $\mathrm{GA}_{3}$ a uma mesma concentração $(2,88 \mu \mathrm{M})$. Entretanto, os brotos oriundos do tratamento T2 (4,5 $\mu \mathrm{M}$ de BAP) ainda mantiveram uma média de crescimento significativamente maior que os oriundos do T0 com crescimento médio de 2,34 $\mathrm{cm}$ e $4,27 \mathrm{~cm}$, respectivamente. Esse fato demonstra que, para Schinus terebinthifolius Raddi, o crescimento dos brotos no tratamento com BAP e $\mathrm{GA}_{3}$ obedece a uma relação aproximadamente linear, demonstrando 


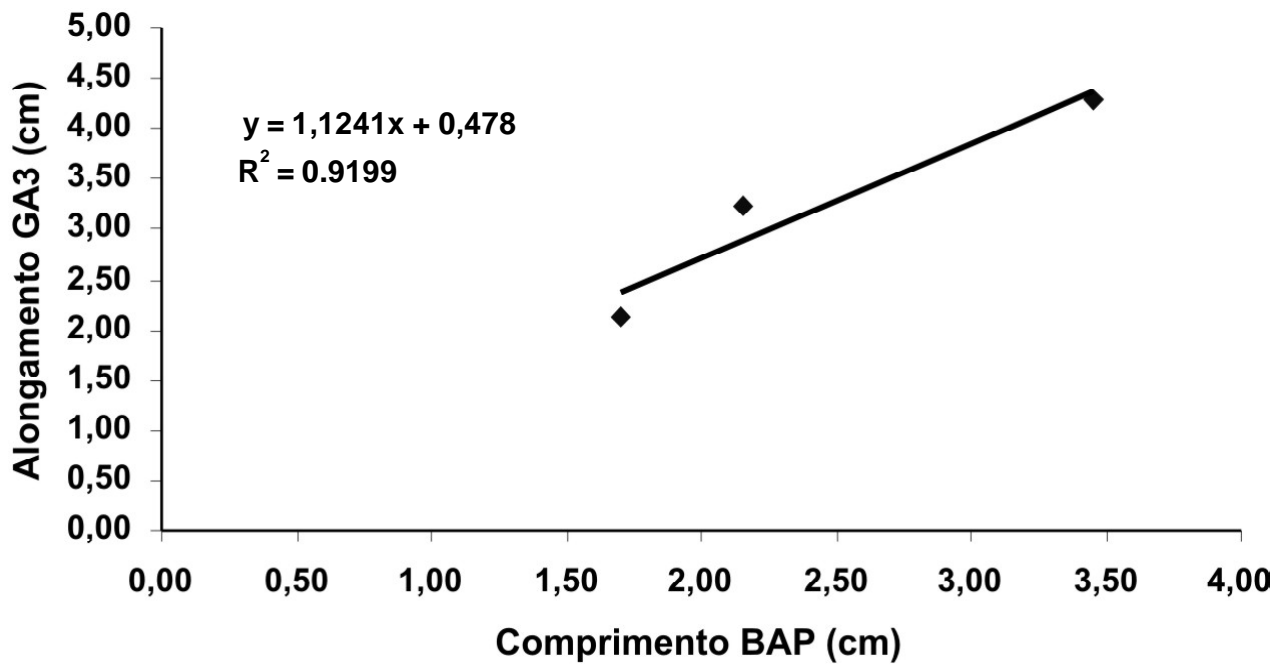

FIGURA 4. Média do alongamento de brotos de Schinus terebinthifolius em $2,88 \mu \mathrm{M}$ de $\mathrm{GA}_{3}$ (ácido giberélico). Brotos oriundos do cultivo de segmentos nodais em diferentes tratamentos, T0: controle; T1:2,25 $\mu$ de BAP; T2: $4,5 \mu \mathrm{M}$ de BAP.

que o crescimento é similar com os dois tipos de hormônios (Figura 4).

\section{CONCLUSÃO}

Para o estabelecimento in vitro da Aroeira da praia, o explante mais indicado é o segmento nodal.

Considerando os parâmetros número e altura média dos brotos, $4,5 \mu \mathrm{M}$ de BAP é a concentração mais responsiva.

O tratamento inicial com o BAP e o alongamento com $\mathrm{GA}_{3}$ possui crescimento aproximadamente linear similar aos dois tipos de hormônios.

\section{REFERÊNCIA}

ANDRADE, M.W. et al. Micropropagação da aroeira (Myracrodruon urundeuva Fr.All). Ciência Agrotecnica, v.24, n.1, p.174-80, 2000

AMORIM, M.M.R. Tratamento da vaginose bacteriana com gel vaginal de aroeira (Schinus terebinthifolius Raddi): ensaio clinico randomizado. Revista Brasileira de Ginecologia, v.25, n.2, p.95-102, 2003.

BOGGETTI, B. et al. In vitro multiplication of cashew (Anacardium occidentale L.) using shoot node explants of glasshouse-raised plants. Plant Cell Reports, v.18, n.4, p.456-61, 1999.
CARVALHO, C.P. et al. In vitro culture of Spondias mombim L. nodal segments. Revista Brasileira de Fruticultura, v.24, n.3, p.776-7, 2002.

DAS, S. et al. In vitro propagation of cashewnut. Plant Cell Reports, v.15, n.6, p.615-9, 1996.

FLORES, R. et al. Regeneração in vitro de espinheira santa (Mautenus ilicifolia Mart.). Revista Brasileira de Agrociência, v.4, n.3, p.201-5, 1998.

GRATTAPAGLIA, D.; MACHADO, M.A. Micropropagação. In:TORRES, A.C.; CALDAS, L.S.; BUSO, J.A. Cultura de tecidos e transformação genética de plantas. Brasília: Embrapa, 1998. p.83-260.

MATOS, F.J.A. Farmácias vivas: sistema de utilização de plantas medicinais projetado para pequenas comunidades. 2.ed. Fortaleza: UFC, 2002. 172p. MURASHIGE, T.; SKOOG, F. A revised medium for rapid growth and bioassays with tobacco tissue cultures. Physiologia Plantarum, v.15, n.3, p.473-97, 1962.

MNENEY, E.E. et al. Clonal propagation of cashew (Anacardium occidentale L.) by tissue culture. Journal of Horticultural Science \& Biotechnology, v.77, n.6, p.649-57, 2002.

OLIVEIRA, A.J.B. et al. In vitro multiplication of Tabernaemontana fuchsiaefolia L. (Apocynaceae). Revista Árvore, v.27, n.4, p.421-5, 2003.

SABÁ, R.T. et al. Micropropagação do jaborandi. Horticultura Brasileira, v.20, n.1, p.106-9, 2002. 